\title{
Level and Factors Associated with Professional Commitment of Health Professionals Providing Institutional Delivery Services in Public Health Facilities, Southwest Ethiopia
}

\author{
Yibeltal Siraneh ${ }^{1}$, \\ Yitbarek $^{1}$, Ayinengida \\ Woldie $^{1}$
}

\author{
Shimeles \\ Adamu1, Belay
}

\author{
Ololo ${ }^{1}$, Gebeyehu
}

Erchafo $^{2}$, Meaza

\author{
Tsega ${ }^{1}$, Kiddus \\ Hailu $^{3}$, Mirkuzie
}

\footnotetext{
OPEN ACCESS

Citation: Yibeltal Siraneh, Shimeles Ololo, Gebeyehu Tsega, Kiddus Yitbarek, Ayinengida Adamu, Belay Erchafo, Meaza Hailu, Mirkuzie Woldie. Level and Factors Associated with Professional Commitment of Health Professionals Providing Institutional Delivery Services in Public Health Facilities of Jimma Zone, Southwest Ethiopia. Ethiop J Health Sci.2017; 28 (4):495.

doi:http://dx.doi.org/10.4314/ejhs.v28i4.15

Received: January 30,2018

Accepted: February 6, 2018

Published: July 1, 2018

Copyright: (C) 2018 Yibeltal Siraneh, et al. This is an open access article distributed under the terms of the Creative Commons Attribution License, which permits unrestricted use, distribution, and reproduction in any medium, provided the original author and source are credited.

Funding:Jimma University granted for our mega research project

Competing Interests: The authors declare that this manuscript was approved by all authors in its form and that no competing interest exists.

Affiliation and Correspondence:

${ }^{1}$ Department of Health Economics, Management, and Policy, Faculty of public health, Institute of health,Jimma University, Ethiopia ${ }^{2}$ Department of Public Health, college of Medicine and Health Sciences, Wachemo University, Ethiopia

${ }^{3}$ Oromia National Regional State, Health Bureau, Primary Healthcare Quality Assurance Expert,Ethiopia Corresponding Author's Email *Email:yibeltal_siraneh@yahoo.com or yibeltalsiraneh@gmail.com
}

\section{ABSTRACT}

BACKGROUND: Professional commitment is beyond a commitment for a particular organization and implies the individuals' perspective towards their profession and the motivation that they have to stay in their job with willingness to strive and uphold the values and goals of the profession. In Ethiopia, uptake of institutional delivery services is low. However, the level and factors associated with professional commitment is not known so far. Hence, our objective is to assess the level and factors associated with commitment of health professionals providing institutional delivery services in public health facilities of Jimma Zone, Southwest Ethiopia.

METHODS: A facility-based cross-sectional study design was conducted from March 01-20, 2016. A total of 442 eligible health professionals were included from randomly selected 7 districts and 47 respective health facilities. Health professionals were requested to fill self-administered questionnaire. After checking its completeness, the data was entered into EPI data version 3.1 and exported to SPSS version 20 for statistical analysis. Factor analysis was conducted. Simple and multiple linear regression were done using 95\%CI and significance was declared at $P<0.05$. All assumptions of linear regression and principal component analysis were checked.

RESULTS: The percentage mean score of professional commitment was $72.71 \%$ (SD21.88). The percentage mean score for perceived maternal health goal scale was $68.37 \%$ with the total variance explained being $69.68 \%$. Perceived staff interaction, work-life balance, affective organizational commitment, normative organizational commitment, personal characteristics and perceived maternal health goal were independent predictors of professional commitment.

CONCLUSION: The percentages mean score of professional commitment was medium. Hence, Health professionals should foster their level of professional commitment to increase uptake of institutional delivery services.

KEYWORDS: Commitment, health professionals, Institutional delivery service uptake 


\section{INTRODUCTION}

Commitment is a willingness to give time and energy to something that is believed in, or a promised to do something and an act of binding oneself intellectually or emotionally to a course of action (1). Commitment of employees is expressed in the form of three mindsets which reflect emotional ties: perceived obligation and perceived sunk costs in relation to the target (2). Thus, measurment of professionals' commitment should tap the target thtat the employee is committed to (3). Commitment can be (a) affective which refers to employees' emotional attachment and identification with, (b) continuance commitment which refers to employees' assessment of whether the costs of leaving within the organization are greater than the costs of staying, (c) normative commitment that refers to employees' feelings of obligation to the organization. Health professionals' commitment to the profession rather than organization could affect their behavior $(4,5,6)$. Professional commitment is beyond a commitment for a particular organization and implies individuals' perspective towards their profession and the motivation that they have to stay in their job (7). Achieving an elevated level of employee's organizational and professional commitment is considered as one of the main goals of human resources management in many companies including the health sector. Indeed, there is a general conviction that professional commitment has a positive impact upon quality, effectiveness and performance of health facilities $(7,8,9)$.

Health professionals' commitment is explained by adherence to principles of ethical practice, effective interaction with clients, reliability, competence, commitment to continuous improvement of competence, pride in profession, appearance, flexibility and good behavior outside work. Studies revealed factors that might affect professional commitment could be personal background, organizational support and commitment, job satisfaction, salary levels, degree of autonomy over work, levels of stress in the work, gender, educational achievement, seniority, diversity of roles occupied, values and attitudes towards the job $(10,11,12,13,14)$.
Institutional delivery service (IDS) is one of the essential maternal health services provided at health facilities by trained and educated health professionals with proficiency in managing normal and complicated pregnancy during child birth, with enabling environment where the equipment, drugs and other supplies required for effective and efficient management of obstetric complications are available. IDS utilization coverage is increasing globaly including Africa, but the progress is very slow in sub-Saharan Afirica including Ethiopia $(15,16)$. In Ethiopia, Ante-natal care (ANC) coverage is found to be in a good status as more than half of women are receiving the service. However, the IDS coverage was still low (national; 16\% and Oromia; 13\%, Jimma zone; $42 \%$ ). Other studies identified factors that affect the reported low level of institutional delivery service uptake but none of them reported factors related with professional commitment (16). Job turnover is typically high among health professionals with seeking of migration and they were serious to change their profession (17), that is why we aimed to determine the level and factors associated with professional commitment of health professionals providing institutional delivery services.

\section{METHODS AND PARTICIPANTS}

Study area and period: The study was conducted in government health facilities of Jimma Zone, Oromia Regional State, Southwest Ethiopia in March 01-20, 2016. The zone is divided into 18 woredas (districts) and one town administration. The zone has four primary hospitals, 114 health centers (96 are functional from which 82 started functioning before 6 months) and 459 health posts. About 1493 health professionals that are relevant for this study were working in the government health facilities of Jimma Zone (18). The coverage of institutional delivery services in Oromia Regional State is $13 \%$ and $42 \%$ in Jimma Zone $(15,16)$.

Study design and population: A facility based cross sectional study design was used. The source population was all health professionals working in government health facilities in Jimma Zone and Jimma Town Adiministration. The study population was all health professionals working in

DOI: http://dx.doi.org/10.4314/ejhs.v28i4.15 
randomly selected woredas and respective public health facilities. All health professionals employed in the health system for at least 6 months and directly involved in the care of pregnant women and institutional delivery service provision were included.

Sample size and sampling technique: Thirty percent $(30 \%)$ of the districts were selected using simple random sampling technique by lottery method from each category of districts, and four primary hospitals taken for the purpose. Category $\mathrm{A}, \mathrm{B}$ and $\mathrm{C}$ districts already decided by the government based on the infrastructure and other remoting criteria to promote and assign health workers accordingly. we took the list of health facilities with respective categories from the Zonal Health Department, and we randomized from each category. All eligible health professionals working in 43 health centers that are found in seven districts, and at four primary hospitals were included. A total of 442 professionals were requested to complete the questionnaire (Figure $1)$.

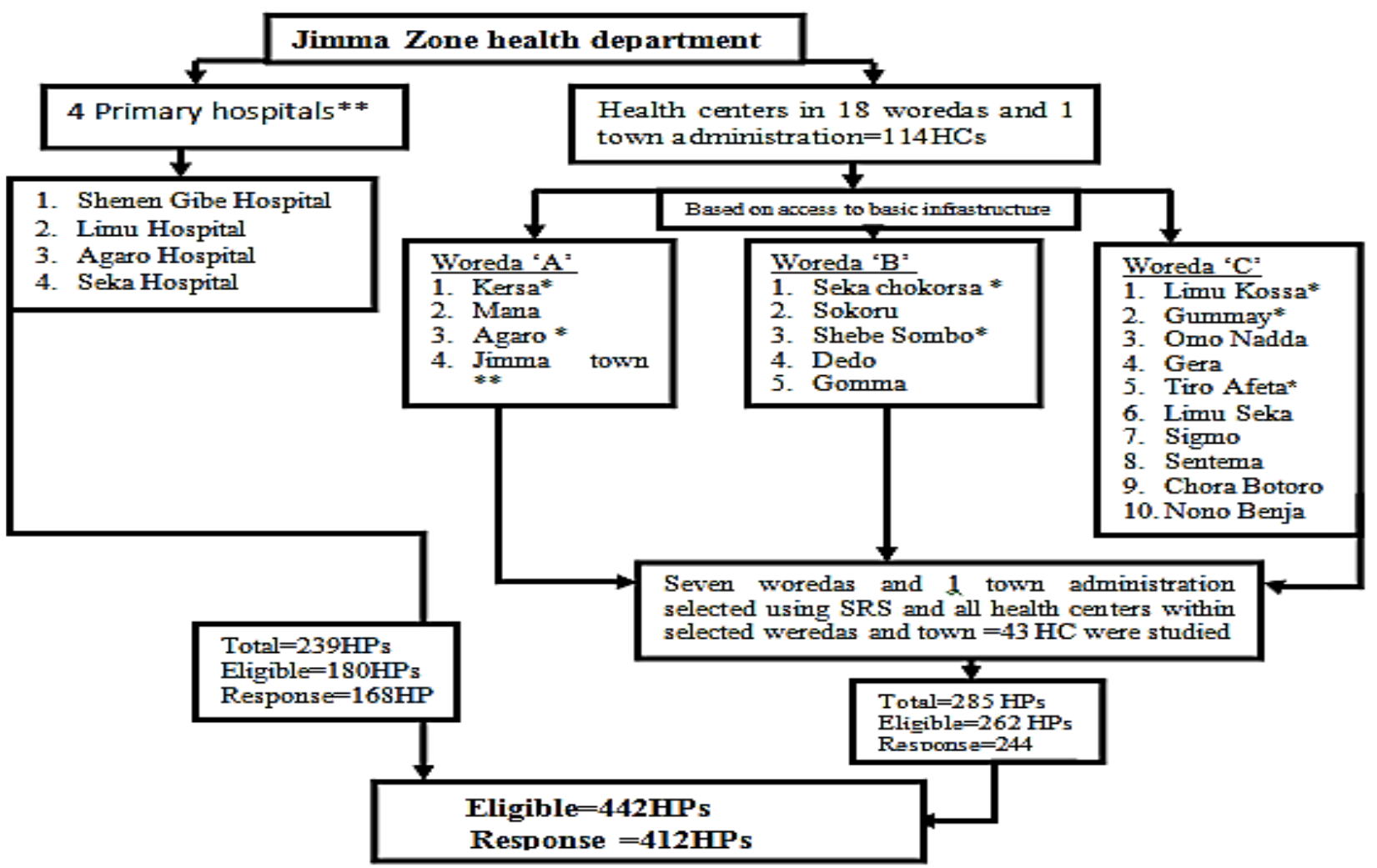

Figure 1: Schematic diagram of sampling procedure of the study, Jimma Zone, 2016

$* *$ Directly taken health facilities, and * $30 \%$ randomly selected districts from each category

Study variable: The dependent variable was professional commitment and the independent variables were socio-demographics, job satisfaction, organizational support, personal characterstics, institutional delivery services and organizational goal and organizational commitment related variables.

Data collection tool: The data were collected using self-administered, structured and pre-tested questionnaire that was adapted from different literatures and translated into Amharic then back into English. The tool contains six parts and has 115 items. Part 1 is on socio-demographic and economic data that comprise 10 items. Part two has 23 items of 5-point Likert scale to measure job satisfaction with 5 sub-components (19). Part 3 contains 30 items of 5-point Likert scale to measure perceived organizational support with 6 
sub-components (20). Part 4 comprises of 10 items with single component that measure professional commitment $(21,22)$, and with this part, organizational commitment was measured using 24 items by three components of commitment each containing 8 items (23). The response categories were 5-point Likert scales ranging from 1 (strongly disagree) to 5 (strongly agree). Part 5 contains 10 items to measure personal characteristics related variables using 5-point Likert scale (24). Part 6 comprises 8 items to measure IDS and organizational goal related variables using 5-point Likert scale (25). Under each dimension, higher score indicates higher perceiption towards the emerged scale.

Professional commitment: It is the relative strength of an individual's linkage to the respective profession. It implies the individual's perspective toward their profession and the motivation that they have to stay in their job that refers to one's loyalty to the profession and the willingness to strive and uphold the values and goals of the profession. This was measured using 10 items of 5-point Likert scale, 1 denoting strongly disagree and 5 denoting strongly agree. Professional commitment score was created, and higher score indicates higher professional commitment.

The mean score for all scales were reported as the percentages of scale mean score $(\% \mathrm{SM})$ after standardized mean value calculated. This value ranges from " $0 \%$ " to " $100 \%$ ". For each case, it was calculated as follows $(26,27)$ :

\section{$\% \mathrm{SM}=$ Actual score - P.minimum $\times 100 \%$ \\ P.Maximum -P.minimum}

Data processing and analysis: The completed questionnaire was coded and entered into a data entry template in EPI-DATA version 3.1 then exported to SPSS version 20 for analysis. The negatively worded items were reverse-coded. All assumptions of linear regression and PCA were checked. Multicollinearity was checked by examining the variance inflation factor. Varimax rotation was employed during factor extraction . Simple linear regression was conducted and significant variables at $p$-value $<0.25$ were taken as candidate for hierarchical multiple linear regression. T-test and one-way ANOVA were used for comparing professional commitment mean score between gender, working facility, professions and qualification. Factors predicting professional commitment were identified using multiple linear regression analysis at a significance level of p-value $<0.05$ with $95 \%$ confidence interval. The reduced final model was constructed using backward model selection method. Split sample validation and outliers detection were done using principal component analysis.

After conducting factor analysis, the name given for each latent component (factor with Eigen value greater than 1 extracted), and the items with scale of reliability coefficient (Cronbach's alpha) of greater than 0.70 were considered. Only items having a communality of $>0.50$ on factor analysis were retained for further analysis. Any item that loaded on more than 1 factor (cross-loaded) was removed (See Table 1). Factor loading $>0.4$ were taken for each of the items and negatively stated items reversely coded.

Ethical consideration: Ethical clearance was obtained from Institutional Review Board (IRB), Jimma University, College of Health Sciences. Permission letter was obtained from Jimma Zone Health Department and respective woreda health offices. Anonymity of the participants was kept. 
Table 1: Summary of Scales emerged from factor analysis as part of the tool using Eigen value greater than one for extraction

\begin{tabular}{|c|c|c|c|c|}
\hline $\begin{array}{l}\text { Parts of the } \\
\text { tool }\end{array}$ & $\begin{array}{l}\text { Name of scale emerged from factor } \\
\text { analysis }\end{array}$ & $\begin{array}{c}\text { No of } \\
\text { items } \\
\text { load on to }\end{array}$ & $\begin{array}{c}\text { Reliability of items } \\
\text { (Cronbach's } \\
\text { Alpha:>0.7) }\end{array}$ & $\begin{array}{c}\text { Total } \\
\text { variability } \\
\text { explained by } \\
\text { the scale } \\
(>60 \%)\end{array}$ \\
\hline \multirow{5}{*}{ Job Satisfaction } & $\begin{array}{l}\text { Perceived working environment/ work } \\
\text { setting scale }\end{array}$ & 5 & 0.853 & \multirow{5}{*}{$68.3 \%$} \\
\hline & $\begin{array}{l}\text { Perceived remuneration and promotion } \\
\text { opportunity scale }\end{array}$ & 5 & 0.817 & \\
\hline & Perceived autonomy at work scale & 4 & 0.835 & \\
\hline & $\begin{array}{l}\text { Perceived professional in/off service training } \\
\text { scale }\end{array}$ & 3 & 0.825 & \\
\hline & Perceived staff interaction scale & 3 & 0.829 & \\
\hline \multirow{6}{*}{$\begin{array}{l}\text { Organizational } \\
\text { Support }\end{array}$} & Perceived HR policy and practice scale & 5 & 0.851 & \multirow{6}{*}{$67.7 \%$} \\
\hline & Perceived facility location scale & 4 & 0.812 & \\
\hline & Perceived work-life balance scale & 3 & 0.780 & \\
\hline & Perceived concern for employee scale & 3 & 0.779 & \\
\hline & Perceived organizational work-load scale & 3 & 0.777 & \\
\hline & Perceived value and care for employee scale & 3 & 0.712 & \\
\hline $\begin{array}{l}\text { Personal } \\
\text { characterstics }\end{array}$ & Perceived personal characteristics scale & 7 & 0.898 & $62.1 \%$ \\
\hline \multirow{2}{*}{$\begin{array}{l}\text { IDS uptake and } \\
\text { Goal }\end{array}$} & Perceived maternal health goal scale & 4 & 0.856 & \multirow{2}{*}{$69.7 \%$} \\
\hline & Perceived IDS provision scale & 4 & 0.852 & \\
\hline \multirow{3}{*}{$\begin{array}{l}\text { Organizational } \\
\text { commitment }\end{array}$} & Continuance commitment scale & 8 & 0.909 & \multirow{3}{*}{$61.8 \%$} \\
\hline & Affective commitment scale & 8 & 0.777 & \\
\hline & Normative commitment scale & 4 & 0.803 & \\
\hline $\begin{array}{l}\text { Professional } \\
\text { commitment }\end{array}$ & Professional commitment scale & 10 & 0.929 & $61.2 \%$ \\
\hline
\end{tabular}

\section{RESULTS}

Socio-demographic characteristics: Among 442 eligible participants, $417(94.3 \%)$ returned the questionnaires. Out of the returned questionnaires, five were discarded due to incompleteness. Considering these, the response rate was $93.2 \%$ (412/442). Little more than half, 228(55.3\%), of the respondents were males. Almost half of the respondents were single in marital status, $202(49 \%)$. The average age of the participants was 27.84 years. The mean work experience at the current health facility was 1.62 years. Nearly onethird, $128(31.1 \%)$, were nurses followed by health officers. $69(16.7 \%)$. Out of 412 professionals, $240(58.3 \%)$ had bachelor degree level of educational qualification which is followed by diploma holders, 158 (38.4\%). Two hundred fortyfour $(59.2 \%)$ participants were from health centers, and $212(51.5 \%)$ of the participants lived in rural areas. One hundred twelve $(27.2 \%)$ of the participants were working in managerial position. The median net monthly salary was 2514 Birr $(\mathrm{IQR}=1700)$, and nearly one-third of $129(31.3 \%)$ of them were paid between 3000-4500 Birr (Table 2) (1 US Dollar $=21.25$ Ethiopian Birr during the data collection period).

Level of Professional commitment: The percentages mean score of health professionals participated in this study was $72.7 \%(\mathrm{SD}=21.88)$. On the other hand, mean raw score of this scale was $39.08 \pm 8.8$ with a total rotated variance explained $(61.2 \%)$ using principal component analysis. Half $(50 \%)$ of them were agreed as they strongly identified with their profession. More than one third reported that they were glad to belong to their profession as agree and strongly agree $(37.4 \%, 34.2 \%)$ (Table 3).

Perceived organizational support predictors: In this model, six factors related with organizational support entered. except perceived human resource policy and practice score $(\mathrm{p}=0.527)$, all factors 
score were significant to be a candidate for multiple linear regression analysis $(p<0.25)$. Perceived value and care for employee score $(\mathrm{p}<0.01, \quad \mathrm{~B}=0.162, \quad 95 \% \mathrm{CI}=0.070, \quad 0.253)$, perceived facility location score $(\mathrm{p}<0.1, \mathrm{~B}=0.088$, $95 \% \mathrm{CI}=-0.004,0.180)$, perceived work-life balance score $(\mathrm{p}<0.01, \mathrm{~B}=-0.122,95 \% \mathrm{CI}=-0.214$,$0.030)$, perceived concern for employee score $(\mathrm{p}<0.01, \mathrm{~B}=-0.157,95 \% \mathrm{CI}=-0.249,-0.065)$ and perceived organizational work-load $(\mathrm{p}<0.01$, $\mathrm{B}=0.162,95 \% \mathrm{CI}=0.070,0.254)$ were significant predictors of professional commitment score. This model explained $30.0 \%$ (adjusted $\mathrm{R}$ square $=0.300, p<0.001)$ of the variability in professional commitment.

Table 2: Socio-demographic characteristics of health professionals working in Jimma Zone goverment health facilities, Oromia Regional State, Southwest Ethiopia, 2016(n=412).

\begin{tabular}{|lll|}
\hline Variables & Categories & No (\%) \\
\hline Sex & Female & $184(44.7)$ \\
& Male & $228(55.3)$ \\
Age in years & $20-24$ & $30(7.3)$ \\
& $25-29$ & $281(68.2)$ \\
& $30-35$ & $62(15)$ \\
Marital & 36 and above & $39(9.5)$ \\
status & Single & $202(49)$ \\
& Married & $195(47.4)$ \\
Work & Widowed/divorced & $15(3.6)$ \\
experience in & in & $231(56.1)$ \\
years & 2.01-5 & $116(28.2)$ \\
Qualification & Diploma & $65(15.8)$ \\
& First-degree/bachelor & $158(38.4)$ \\
Residence & Postgraduate & $240(58.3)$ \\
& Urban & $14(3.4)$ \\
Type of & Rural & $200(48.5)$ \\
facility & Health center & $212(51.5)$ \\
Type of post & Hospital & $244(59.2)$ \\
& Managerial & $168(40.8)$ \\
Profession & None managerial & $112(27.2)$ \\
category & Nurse & $300(72.8)$ \\
& Midwifery & $128(31.1)$ \\
& Health officer & $62(15)$ \\
& Medical lab & $69(16.7)$ \\
& Pharmacist/druggist & $53(12.9)$ \\
& GP/medical doctor & $47(11.4$ \\
& Others** & $30(7.3)$ \\
& & $23(5.6)$ \\
\hline
\end{tabular}

${ }^{* *}$ Others: ESO and anesthesia
Job satisfaction predictors: Five factors related with job satisfaction entered into the model. Out of these, four were significant predictors of professional commitment. Perceived staff interaction was the strongest predictor $(\mathrm{B}=0.326,95 \% \mathrm{CI}=0.237,0.415, \mathrm{p}=0.000)$ followed by perceived autonomy at work $(\mathrm{B}=0.124$, $95 \% \mathrm{CI}=0.035,0.213, \mathrm{p}=0.007)$. The other two predictors were perceived professional in/off service training $\quad(B=0.061,95 \% \mathrm{CI}=0$ $.028,0.150, \mathrm{p}=0.178)$ and perceived working environment/work setting $(\mathrm{B}=0.057,95 \% \mathrm{CI}=-$ $0.032,0.146, \mathrm{p}=0.207)$.However, perceived remuneration and promotion opportunity had no significant relation with professional commitment score $(\mathrm{P}=0.538)$. Almost $13 \%$ of the variance in professional commitment was explained by this model (adjusted $\mathrm{R}$ square $=0.127, \mathrm{P}<0.001$ ). Organizational commitment predictors: Three factors related with organizational commitment components were entered into the model. Out of these, two were significant predictors of professional commitment. Both affective commitment score $\quad(B=0.264,95 \%$; $\mathrm{CI}=0.180,0.349, \mathrm{P}=0.000) \quad$ and normative commitment score $\quad(B=0.403,95 \%$; $\mathrm{CI}=0.319,0.488, \mathrm{P}=0.000$ )were stronger predictors, and normative commitment score was the strongest among all. However, continuance commitment score was not significant predictor of professional commitment $(\mathrm{P}=0.572)$. About $23.2 \%$ of the professional commitment variability was explained by the model.

Perceived personal characteristics and institutional delivery services uptake predictors: Three factors related with perceived personal characteristic and IDS uptake were entered into the multiple linear regresion model. Out of these, two were significant predictors of professional commitment. Both personal characteristics score $\quad(\mathrm{B}=0.412$, $95 \% \mathrm{CI}=0.303,0.522, \mathrm{P}=0.000)$ and maternal health goal score $\quad(\mathrm{B}=0.227,95 \% \mathrm{CI}=0.117, \quad 0.336$, $\mathrm{P}=0.000)$ were stronger predictors, and personal characteristics score was the strongest among all. Howevr, institutional delivery service provision factor score was not a significant predictor of professional commitment $(\mathrm{P}=0.461)$. Almost $36 \%$ of the professional commitment variability was

DOI: http://dx.doi.org/10.4314/ejhs.v28i4.15 
explained by this model (adjusted $\mathrm{R}$ square $=0.355, \mathrm{P}=0.000$ ).

Independent predictors of professional commitment:The final model explained almost $45 \%$ (Adjusted R Square $=0.445$ ) of the variability in the professional commitment factor score. None of the Socio-demographic and economic variables were significant predictor in the final model (See Table 4).

Table 3: Frequency distribution of five point Likert scale response of participants for professional commitment measuring items, Jimma zone, $2016(n=412)$.

\begin{tabular}{|llllll|}
\hline Items measuring professional commit & $\begin{array}{l}\text { Strongly } \\
\text { disagree }\end{array}$ & Disagree & Neutral & Agree & $\begin{array}{l}\text { Strongly } \\
\text { agree }\end{array}$ \\
\hline $\begin{array}{l}\text { I am willing to put in a great deal of effort to } \\
\text { develop my profession beyond expected }\end{array}$ & $39(9.5 \%)$ & $38(9.2 \%)$ & $33(8 \%)$ & $181(43.9 \%)$ & $121(29.4 \%)$ \\
$\begin{array}{l}\text { I am a person who identifies strongly with } \\
\text { my profession }\end{array}$ & $20(4.9 \%)$ & $35(8.5 \%)$ & $30(7.3 \%)$ & $206(50 \%)$ & $121(29.4 \%)$ \\
$\begin{array}{l}\text { I would accept almost any type of job that } \\
\text { related to my profession to keep working } \\
\text { beyond expected from me }\end{array}$ & $22(5.3 \%)$ & $39(9.5 \%)$ & $33(8 \%)$ & $197(47.8 \%)$ & $121(29.4 \%)$ \\
$\begin{array}{l}\text { I am a person who feels strong ties with } \\
\text { other members of my profession }\end{array}$ & $12(2.9 \%)$ & $43(10.4 \%)$ & $43(10.4 \%)$ & $199(48.3 \%)$ & $115(27.9 \%)$ \\
$\begin{array}{l}\text { I am a person who is proud to belong to my } \\
\text { profession }\end{array}$ & $18(4.4 \%)$ & $46(11.2 \%)$ & $29(7 \%)$ & $173(42 \%)$ & $146(35.4 \%)$ \\
$\begin{array}{l}\text { My profession really inspires the very best in } \\
\text { me in the way of job performance }\end{array}$ & $19(4.6 \%)$ & $50(12.1 \%)$ & $29(7 \%)$ & $177(43 \%)$ & $137(33.3 \%)$ \\
$\begin{array}{l}\text { I am extremely glad that I chose this } \\
\text { profession to work for ever in advance }\end{array}$ & $32(7.8 \%)$ & $56(13.6 \%)$ & $29(7.0 \%)$ & $154(37.4 \%)$ & $141(34.2 \%)$ \\
$\begin{array}{l}\text { I am a person who criticizes my profession } \\
\text { I am a person who considers my profession } \\
\text { to be important }\end{array}$ & $166(40.3 \%)$ & $165(40 \%)$ & $39(9.5 \%)$ & $24(5.8 \%)$ & $18(4.4 \%)$ \\
$\begin{array}{l}\text { I am a person who tries to hide belonging to } \\
\text { my profession }\end{array}$ & $157(38.1 \%)$ & $184(44.7 \%)$ & $31(7.5 \%)$ & $23(5.6 \%)$ & $17(4.1 \%)$ \\
\hline
\end{tabular}

A one unit increment in perceived staff interaction score resulted in 0.089 unit increase in the professional commitment score of health professionals (95\%CI: $0.010,0.168 ; \mathrm{P}<0.01)$. One unit increment in the perceived work-life balance score of the professionals increases their professional commitment score by 0.147 (95\%CI: $0.020,0.172, \mathrm{P}<0.001)$. The other predictor variable of professional commitment was organizational affective commitment score. It was found that a unit increment in the organizational affective commitment score leads to an increment of professional commitment score by 0.151 $(95 \% \mathrm{CI}=0.071,0.230, \mathrm{P}<0.001)$. A unit increase in the organizational normative commitment score results in increment of 0.238 units in the professional commitment score $(95 \% \mathrm{CI}=0.159$, $0.318, \mathrm{P}=0.000)$. The strongest predictor of professional commitment was perceived personal characteristics score followed by NOC. It was found that a unit increment in the personal characteristics score leads to an increment of

Table 4: Independent predictors of professional commitment of health professionals, Jimma Zone, government facilities, SW Ethiopia, 2016 ( $\mathrm{n}=412)$ (multivariable linear regression).

\begin{tabular}{|c|c|c|c|c|}
\hline Variables & $\begin{array}{l}\text { Unstandardized } \\
\text { Coefficients B } \\
\end{array}$ & $P$ value & $\begin{array}{r}95 \% \text { CI } \\
\text { Lower Bound } \\
\end{array}$ & $\begin{array}{l}\text { for B } \\
\text { Upper Bound }\end{array}$ \\
\hline Perceived working environment/ work setting factor score & -.066 & .083 & -.141 & .009 \\
\hline Perceived professional in/off service training factor score & .062 & .093 & -.010 & .135 \\
\hline Perceived staff interaction score & .089 & $.007 *$ & .010 & .168 \\
\hline Perceived work-life balance factor score & .147 & $.000 * *$ & .020 & .172 \\
\hline
\end{tabular}

DOI: http://dx.doi.org/10.4314/ejhs.v28i4.15 
Affective organizational commitment factor score

Normative organizational commitment factor score

Personal character factor score

Perceived maternal health goal factor score
.151

.238

.307

.154

$.000 * * \quad .071$

$.000 * * \quad .159$

$.000 * * \quad .200$

$.004 * \quad .050$
.230

.318

.414

.259

Constant $=0.007$, Adjusted R Square $=0.445$, *significant at $\mathrm{p}$ value $<0.05, * *$ significant at $\mathrm{p}$ value $<0.001$, dependent variable:professional commitment factor score $( \pm 3)$, Max VIF $=1.06$ (no multicolinearity: at VIF<5)

professional commitment score by 0.307 $(95 \% \mathrm{CI}=0.200, \quad 0.414, \quad \mathrm{P}<0.001)$. There is a positive predictive relationship between professional commitment score and perception of maternal health goal score. It was found that a unit increment in the perception of maternal health goal score leads to an increment of professional commitment score by 0.154 $(95 \% \mathrm{CI}=0.050,0.259, \mathrm{P}<0.001)$ (Table 4).

\section{DISCUSSION}

Our study pointed out that professional commitment percentage mean score of health professionals was $72.7 \%$ (SD21.88) which is lower than a result reported from India, where the professional commitment percentages mean score was $85.9 \%(n=440)(9)$. The difference in $\% \mathrm{SM}$ may be due to the Indian government's provision of better work environment to its health workforce and better opportunities for career growth and development. Additionally, the majority of the study participants were doctors that had good relations with superiors and clarity on job objectives; autonomy on work could also help in delivering responsibilities professionally to have enhanced professional commitment percentage mean score in the Indian case (9). Our finding $(\% \mathrm{SM}=72.7 \%)$ showed that there is a higher level of commitment as compared to results of other studies conducted in Saud Arabia, Nigeria and Taiwan where the professional commitments mean scores were $57.4 \%, 55.2 \%$ and $67 \%$ respectively $(28,29)$. This difference may be due to the low reward provided to the health care workers in the Nigerian case. Participants of the study were only nurses that reported higher workload and stress in the case of Taiwan and Saud Arabia than our study participants' who were from all types of profession. Our study revealed that professional commitment was found to be higher than their commitment to their organization which is supported by facility based cross sectional study finding from India, where doctors were more identified with their profession than with organization (9).

Our finding showed that perceived worklife balance factor score was one of the predictors of professional commitment. Several studies had also demonstrated that if employees have reasonable leisure time, they will be more likely to be committed to the profession as compared to those who do not balance thier work and life $(30,31)$. The reason why satisfaction with organizational support leads to enhanced commitment is that a higher level of job satisfaction may lead to good work-life balance and reduction in stress (32). In a study conducted in Iran, health professionals facing work overload and stress experience work-life imbalance due to terrible consequences and challenges with different feelings (life and death situation) (3). Organizational affective (affection for job) commitment and normative (sense of obligation to stay) committed are predictors of professional commitment which is supported by others findings. Affective component (AC) is adoption of organizational goals and commitment to them and having positive emotions related to identification with it. When workers feel a sense of obligation to their organization, this sense of obligation can stem from several factors. They might feel that they should remain within the organization because it has invested in many ways and become committed professionally $(5,24,33)$. Our study result is almost consistent with the research findings in India that revealed $56.7 \%$ for AOC and $57.3 \%$ for NOC (9). Our study revealed that more than half of the respondents reported a high-level of organizational (affective) commitment which is less than the other study output in which almost two-thirds of the respondents reported a high-level of organizational (affective) commitment $(\mathrm{n}=326$, $63.7 \%$ ) (34). This decreament may be due to the remote facility location and infrastructure limitations in Jimma Zone that decreased their 
affection towards the organizations or health facilities.

Personal characteristic was the strongest predictor of professional commitment that indicates that being committed to one's profession is explained by adherence to principles of ethical practice, effective interaction with clients, reliability, competence, commitment to continuous improvement of competence, pride in profession, appearance, flexibility and good behavior outside work. Our finding is consistent with the finding of a longitudinal study conducted in Norway where the level of professional commitment was negatively associated with substance use which concluded that professionals involved in substance use displayed lower levels of work commitment than those who were abstaining or merely exposed $(\mathrm{P}<0.05)(35)$.

We found that perceived maternal health goal score is one of the strongest predictor. This is supported by the other study which stated as a low-level of role conflict and role ambiguity due to shared vision they had and aware of their responsibilities affect professional commitment. Our finding showed that those who score higher for perceived maternal health goal were dedicated to provide the service that enhance their professional commitment. This is supported by a study conducted in Iran that depicted as health worker who is committed to offer the best health care will increase once commitment to the profession. Hence, feeling responsibility is most important aspect of professional commitment that increases loyalty and tendency to remain in the profession.Therefore, professionals' perceptions towards the service goal and uptake status affect their level of commitment (3). The comparison test in our study revealed that professional commitment was significantly different between qualifications: diploma (\% mean score $=74.2)$ and postgraduate $(\%$ mean score $=66.4$ ). Similarly, other studies revealed the same result showing that nurses with bachelor degree and above reported lower levels of professional commitment as compared to diploma holders $(p<0.05)(9,14)$.

In conclusion, the level of professional commitment was medium affected by percieved staff interaction, work-life balance, affective organizational commitment, normative organizational commitment, personal characteristics and percieved maternal health goal. Perception towards the maternal health goal affects the level of professional commitment. Existence of shared vision and clear or common goal with smart objectives towards institutional delivery service provision enhance health professionals'commitment that will ultimately increase service uptake.

\section{ACKNOWLEDGMENT}

We would like to extend our gratitude to Jimma University, College of Health Sciences, Department of Health Economics, Management and Policy for giving the chance to work on such relevant topic in the mega-research project granted by Jimma University. We would like to thank the data collectors, study participants, Jimma Zone health Department and woreda health offices.

\section{REFERENCES}

1. Sally Wehmeir. Oxford advanced learner's dictionary of current English/A.S. Hornby. Seventh edition. 1999;7:850

2. Allen $\mathrm{N}$ and Meyer J. The measurement and antecedents of affective, continuance, and normative commitment to the organization. Journal of Occupational Psychology. 1990; 63:1.

3. Fateme J, Neda M, Soroor P. Influencing factors on professional commitment in Iranian nurses. A qualitative study,journal of medical science. 2011;50:35-37

4. Mowday RT, Porter LW and Steers RM. Employee-Organization Linkages: The Psychology of Commitment, Absenteeism, and Turnover. Academic Press: New York. 1982.

5. Meyer $\mathrm{J}$ Allen N. A three-component conceptualization of organizational commitment. Human Resource Management Review. 1991; 1(1): 61-89.

6. Meyer J, Allen N. Commitment in the workplace. Thousand Oaks, SAGE Publications; 1997.

7. Gallagher D and Mclean Parks J. Contingency Commitment and the Contingent Work Relationship. Human Resource Management Review. 2001; 11: 181-208.

8. Gary Blau. Early-career job factors influencing the professional commitment of medical technologists. Academy of management journal. 1999; 42 (6):687-695.

9. Sunil Mahesh wari, Ramesh Bhatand Somen Saha. Commitment among state health officials an

DOI: http://dx.doi.org/10.4314/ejhs.v28i4.15 
its implications for health sector reform: Lessons from Gujarat Indian Institute of Management Ahmedabad. Indian Journal of Med Res. 2008; 27: $148-153$

10. Clausen T, Borg V. Do positive work-related states mediate the association between psychosocial work characteristics and turnover? A longitudina analysis. Int JStress Manag. 2010;17:308- 324

11. Hinshaw A, Gerber R, Atwood J and Allen J. The use of predictive modeling to test nursing turnover. Nursing Research, 1983; 32(1): 35-42.

12. Parasuraman S. Nursing turnover: An integrated model. Research in Nursing and Health; 1989; 12(4): 267-277.

13. Mowday R, Porter L and Dubin R. Unit Performance, Situational Factors, and Employee Attitudes in Spatially Units. Organizations behavior and Human Performance, 1974; 12:231.

14. Government of Ethiopia and the World Bank. Health Sector Review, Ethiopian social sector studies. Mega, Addis Ababa, Ethiopia; 2008:40.

15. United Nations Population Fund. Trends in Maternal Health in Ethiopia: In-depth Analysis of the Ethiopia demographic and health survey 20002011.challenges in achieving the millennium development goals for maternal mortality, Addis Ababa, Ethiopia. 2012:12

16. Central statistics Agency. Ethiopia demographic and health surey-mini report. Addis Ababa, Ethiopia. 2014:10

17. Serra D, Serneels P, Lindelow and Montello J. Health workers' career choices and early work experience in Ethiopia, World Bank working paper. Washington, DC; 2010:56.

18. Oromia Regional State, Jimma Zone health Department annual activity report on Maternal and child health services, Jimma, 2007 E.C.

19. Weiss D. Dawis R. England G.and Lofquist L. Manual for the Minnesota Satisfaction Questionnaire. Industrial Relations Center, University of Minnesota, 1967.

20. University of Delaware: Format for the 8-item Survey of Perceived Organizational Support, 1984.

21. Siew L, Chitpakdee B, Chontawan R. Factors Predicting Organizational and professional Commitment among Nurses in State Hospitals of Malaysia. IMJM. 2011; 10(2): 234-40.

22. Chan P, Chou Y, Cheng F. Career needs, career development programmes, organizational commitment and turnover intention of nurses in Taiwan. Journal of Nursing Management. 2007; 15: 801-810.
23. Meyer JP, Maltin ER. Employee commitment and well-being: a critical review, theoretical framework and research agenda. J Vocat Behav. 2010;77:323 - 337

24. Cheng Y, Stockdale M. The validity of the threecomponent model of organizational commitment in a Chinese context. J Vocal Behav. 2003; 62: 465-489.

25. Hong Lu. Job satisfaction and its related factors: A questionnaire survey of hospital nurses in Mainland China. International Journal of Nursing Studies. 2007; 44:574-588.

26. Reid path D. Chan K: A method for the quantitative analysis of the layering of HIV related stigma. AIDS Care, 2005; 17(4):425-432.

27. Feyissa GT, Abebe L, Girma E, Woldie M. Stigma and discrimination against people living with HIV by healthcare providers, Southwest Ethiopia. $B M C$ Public Health. 2012; 12:522-542.

28. Akanbi K, Ayobami P, Itiola A. Exploring the Relationship between Job Satisfaction and Organizational Commitment among Health Workers in Ekiti State, Nigeria. Journal of Business and Management Science. 2013;1(2): 18.

29. Huang S. The Relationships between professional Commitment and Job Satisfaction, and Their Predictive Factors in the Nurses. Journal of Applied Nursing Research, 2009; 2(4): 15-20.

30. Ahmed S. Job satisfaction and organizational commitment for nurses. Saudi Medical Journal. 2000; 21 (6): 531-535.

31. Wen-Hsien $\mathrm{H}$, Ching $\mathrm{C}$, Ying-Ling $\mathrm{S}$ and RongDa L. Effects of job rotation and role stress among nurses on job satisfaction and organizational commitment. Journal of BMC Health Services Research. 2009; 9:8-20.

32. Pourreza A, Akbari F, Ramesh N, Aghlmand S. Job satisfaction on primary health care providers in the rural Settings. Iranian J Public Health. 2007; 36(3): 64-70.

33. Wasti S. Commitment profiles: Combinations of organizational commitment forms and job outcomes. J. Vocal Behav, 2005; 67: 290-308.

34. Mowday T. Steers R.and Porter W. The measurement of organizational commitment. Journal of Vocational Behavior. 1979;14(2): 224.

35. Christer Hyggen. Norwegian Social Research (NOVA), Postboks 3223 Elisenberg, Oslo. 2012.

DOI: http://dx.doi.org/10.4314/ejhs.v28i4.15 